\title{
The validity of the triage system ADAPT
}

\author{
Martin Nordberg ${ }^{1^{*}}$, Sven Lethvall ${ }^{2}$, Maaret Castrén ${ }^{1}$ \\ From Danish Society for Emergency Medicine: Research Symposium 2010 \\ Roskilde, Denmark. 20-21 May 2010
}

\section{Background}

Adaptive process triage (ADAPT) is a triage system developed in Sweden in 2006. It is currently used by four University hospitals in the region of Stockholm and several other hospitals in Sweden. It is introduced in several hospitals in Denmark. ADAPT is based on a trace and trigger tool for vital signs according to the $\mathrm{ABCD}$-principle and a short systematic questionnaire for each chief complaint. The main objective is detection of the seriously ill, guidance of healthcare personnel for patient streaming and to be a communication tool. The triage system is based on lean-principles and modern ideas for patient streaming to very urgent care, urgent care, admitting of the elderly and to 'see and treat'. Following ADAPT each patient are triaged as either red (life-threatening), orange (seriously ill), yellow (ill), green (need of assessment) or blue (fast-track).

The aim of this study is to assess the validity of ADAPT as a triage system.

\section{Methods}

All patients visiting the ED at Södersjukhuset in July December 2008 were eligible for inclusion. Only the first visit of each patient in that time period was recorded. All adult patients visiting (excluding gynaecology and obstetrics) were included. Need for admittance to a ward or ICU was used as outcome parameters. Pearson Chi-square test and Fischers' exact test was used for statistical assessment of the distribution in the outcome parameters.

\section{Results}

$\mathrm{N}=35054$. Out of these $4.2 \%$ were triaged as red, $15.6 \%$ orange, $36.6 \%$ yellow, $28.7 \%$ and $14.8 \%$ blue.

The red group was admitted to a general ward in $77.5 \%$, orange in $55.6 \%$, yellow in $36.3 \%$, green in $14.9 \%$

\footnotetext{
* Correspondence: martin.nordberg@sodersjukhuset.se

${ }^{1}$ Karolinska Institutet, Dept of clinical science and education, Sweden
}

Full list of author information is available at the end of the article and blue in $2.0 \%$. There was statistical significance $(\mathrm{p}=.000)$.

The red group was admitted to ICU in $24.7 \%$ of the cases, orange in $4.6 \%$, yellow in $1.1 \%$ yellow, green in $0.2 \%$ and blue in $0.0 \%$. There was statistical significance $(\mathrm{p}=.000)$.

\section{Conclusion}

Our study show that ADAPT triage levels are good predictors of the need for admittance to a general ward as well as a good predictor of the need for intensive care.

Author details

'Karolinska Institutet, Dept of clinical science and education, Sweden. ${ }^{2} \mathrm{Herlev}$ Hospital, Denmark.

Published: 17 September 2010

doi:10.1186/1757-7241-18-S1-P36

Cite this article as: Nordberg et al:: The validity of the triage system ADAPT. Scandinavian Journal of Trauma, Resuscitation and Emergency Medicine 2010 18(Suppl 1):P36.

\section{Submit your next manuscript to BioMed Central and take full advantage of: \\ - Convenient online submission \\ - Thorough peer review \\ - No space constraints or color figure charges \\ - Immediate publication on acceptance \\ - Inclusion in PubMed, CAS, Scopus and Google Scholar \\ - Research which is freely available for redistribution \\ Submit your manuscript at www.biomedcentral.com/submit}

